\title{
Codeswitching entre línguas de sinais e as escolhas linguísticas de surdos venezuelanos no Brasil
}

\section{Codeswitching between sign languages and the linguistic choices of Venezuelan deaf people in Brazil}

\section{Cambio de lenguas entre lenguas de señas y las elecciones lingüísticas de las personas sordas venezolanas en Brasil}

\author{
iD) Rodrigo Mesquita \\ Universidade Federal de Roraima (UFRR), Boa Vista, Roraima, Brasil. \\ E-mail: rodrigomesquitago@hotmail.com. \\ iD Alessandra Cruz \\ Centro de Ciências Humanas e Letras, Universidade Federal de Roraima (UFRR), Boa \\ Vista, Roraima, Brasil. \\ E-mail: alessandra.letraslibras@gmail.com
}

Resumo: O artigo analisa a correlação entre o uso de codeswitching por imigrantes surdos venezuelanos bilíngues que vivem no Brasil e os fatores sociais e situacionais que explicam preferências e intenções dos indivíduos. Propõe-se como objetivo rastrear processos inferenciais através dos quais as escolhas linguísticas dos indivíduos transmitem evidências sobre os processos identitários e relações interpessoais que configuram algumas de suas interações cotidianas. A etnografia da comunicação (HYMES, 1972; 1986) orientou os procedimentos teórico-metodológicos de coleta de dados. Os modelos de Escolha Racional (MYERS-SCOTTON; BOLONYAl, 2001) e de Marcação (MYERS-SCOTTON, 1993) dão o suporte teórico para a análise dos dados, indicando que as escolhas linguísticas 
dos imigrantes foram orientadas para uma melhor adaptação a um novo contexto e a busca por melhores condições de vida.

Palavras-chave: Bilinguismo individual. Codeswitching. Língua de sinais venezuelana. Libras.

Abstract: The article analyzes a correlation between the use of codeswitching by bilingual deaf immigrants from Venezuela who are living in Brazil with the social and situational factors that explain the use individuals' intentions. The goal is to track inferential processes through which individuals' linguistic choices convey evidence about the identity processes and interpersonal relationships that shape some of their everyday interactions. The ethnography of communication (HYMES, 1972 ; 1986) guides the theoretical and methodological procedures for data collection. The rattional choice theory (MYERS-SCOTTON; BOLONYAI, 2001) and the markednnes model (MYERS-SCOTTON, 1993) provide theoretical support for data analysis, which indicated how the linguistic options of immigrants were oriented towards a better adaptation to the new context and the search for better living conditions.

Keywords: Individual bilingualism. Codeswitching. Venezuelan Sign Language. Libras.

Resumen: Este artículo analiza la correlación entre el uso del codeswitching por inmigrantes sordos venezolanos bilingües que viven en Brasil y los factores sociales y situacionales que explican las preferencias e intenciones de estos individuos. El objetivo es rastrear los procesos inferenciales por medio de los cuales las elecciones lingüísticas de los individuos transmiten evidencias sobre los procesos de identidad y las relaciones interpersonales que dan forma a algunas de sus interacciones cotidianas. La etnografía de la comunicación (HYMES, 1972; 1986) guió los procedimientos teóricos y metodológicos de la recopilación de datos. Los modelos teóricos Rattional Choice (MYERS-SCOTTON; BOLONYAI, 2001) y Markednnes Model (MYERS-SCOTTON, 1993) son utilizados como apoyo teórico para el análisis de datos, que indicaron que las opciones lingüísticas de los inmigrantes se han orientado hacia una mejor 
adaptación a un nuevo contexto y a la búsqueda de mejores condiciones de vida.

Palabras clave: Bilingüismo individual. Cambio de código. Lengua de señas venezolana. Libras.

Submetido em 30 de junho de 2020.

Aceito em 27 de novembro de 2020.

Publicado em 22 de março de 2021. 
Codeswitching entre línguas de sinais e as escolhas linguísticas de surdos venezuelanos no Brasil Rodrigo Mesquita - Alessandra Cruz

\section{Introdução}

A diversidade linguística, o contato entre línguas e as configurações de um contexto específico de bilinguismo que envolve línguas minoritárias são os pontos focais do presente artigo. Mais especificamente, buscamos, no contexto fronteiriço de Boa Vista, capital do estado de Roraima, investigar as razões que levam falantes/sinalizantes ${ }^{1}$ surdos bilíngues a realizarem escolhas linguísticas envolvendo a Libras e a Lengua de senãs venezolana (ou Língua de sinais venezuelana - daqui em diante, LSV), ambas línguas de sinais em condição minoritária em seus respectivos países (GÓES; LACERDA, 2000; MORALES, 2006).

Como característica do macrocontexto que dá contorno aos eventos de fala e interações analisadas em que há ocorrência de codeswitching² (doravante, CS), destaca-se o crescimento da (já grande) diversidade sociocultural e linguística do estado de Roraima desde o agravamento da crise política e econômica venezuelana em 2014, o que resultou na imigração em massa para vários países sul-americanos, incluindo o Brasil. Boa Vista, localizada a aproximadamente duzentos quilômetros da fronteira, já registrava, em 2018, mais de 25 mil venezuelanos, o equivalente a sete e meio por cento da população da capital ${ }^{3}$.

Do lado brasileiro, a LSV se encontra em situação duplamente minoritária, uma vez que, além de já marginalizada em relação ao espanhol na Venezuela, também o é em relação ao português no Brasil e, como procuramos mostrar neste artigo através da análise do CS, encontra solidariedade na Libras e seus usuários.

Ao considerarmos que indivíduos bilíngues podem decidir sobre qual língua irão utilizar em cada interação e mesmo alternar entre as línguas ou mesclá-las, o CS, em uma definição ampla,

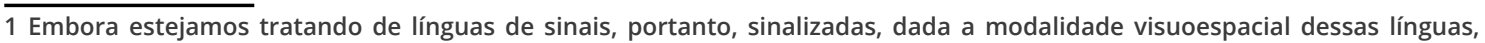
utilizaremos o termo "sinalizantes" de forma intercambiável com "falantes", pelo motivo de os modelos teóricos adotados, a princípio pensados para línguas orais, utilizarem o último termo de forma mais recorrente.

20 termo codeswitching (CS) é também conhecido, no Brasil, como alternância entre línguas ou alternância de códigos. 0 termo em inglês será adotado neste artigo por compor a terminologia utilizada no aparato teórico utilizado para as análises, assim como também é amplamente utilizado na literatura internacional e nacional sobre o tema.

3 Para saber mais sobre a diversidade sociolinguística de Boa Vista, veja Mesquita (2020). 
Codeswitching entre línguas de sinais e as escolhas linguísticas de surdos venezuelanos no Brasil Rodrigo Mesquita - Alessandra Cruz

nomeia o fenômeno caracterizado pelo uso alternado de dois ou mais códigos (que podem ser línguas ou mesmo variedades delas) por indivíduos bilíngues numa mesma situação de interação (GROSJEAN, 1982).

Do ponto de vista social, contextos de bilinguismo podem ser tão diversos quanto os fatores que atuam sobre suas configurações, o que proporciona uma gama de perspectivas através das quais o bilinguismo pode ser analisado. Análises do bilinguismo social através da perspectiva sociolinguística têm como principal contribuição, conforme Myers-Scotton e Boloniay (2001, p. 5), "demonstrar que existem de fato macropadrões previsíveis e uma hierarquia entre os fatores de identidade social associados à variação nos padrões". Além disso, as autoras reconhecem as contribuições da Análise da Conversação para o conhecimento da intricada organização da conversa cotidiana.

Igualmente, na análise do bilinguismo individual estão envolvidos fatores de diferentes naturezas. No entanto, é somente neste nível de análise, como apontam Myers-Scotton e Boloniay (2001), que é possível obter explicações adequadas para a variação individual nas escolhas linguísticas orientadas para o comportamento dos demais envolvidos nas interações. É neste nível que se dão as análises, neste artigo, do uso alternado (ou CS) da LSV e Libras por indivíduos bilíngues venezuelanos surdos que se encontram na condição de imigrantes na capital roraimense, com o objetivo de rastrear processos inferenciais através dos quais as escolhas linguísticas dos indivíduos transmitem evidências sobre os processos identitários e relações interpessoais que configuram algumas de suas interações cotidianas.

O pressuposto básico adotado neste artigo, seguindo o Modelo de Marcação (Markednnes Model) de Myers-Scotton (1993) e a teoria de Escolha Racional (Rational Choice Theory - MYERS-SCOTTON; BOLONIAY, 2001), é de que, tal qual um interruptor que aciona um mecanismo qualquer, o que "aciona" uma determinada escolha linguística são as intenções e avaliações que os indivíduos calculam para otimizar as recompensas das interações, levando em conta suas motivações subjetivas e oportunidades objetivas. Por sua vez, 
Codeswitching entre línguas de sinais e as escolhas linguísticas de surdos venezuelanos no Brasil Rodrigo Mesquita - Alessandra Cruz

há a pressuposição de que a escolha de formas linguísticas em detrimento de outras é um comportamento intencional, conforme preconizou Grice (1975 apud MYES-SCOTTON, 1993), guiado pela racionalidade, que é um "mecanismo universalmente disponível para os seres humanos" (MYERS-SCOTTON; BOLONIAY, 2001, p. 5).

O banco de dados, constituído inicialmente para a pesquisa de Cruz (2019) - que investigou motivações sociopragmáticas do CS envolvendo o par de línguas de sinais - é revisitado para uma análise complementar, orientada pelos pressupostos teóricos supracitados. A coleta de dados, realizada entre 2017 e 2019, na cidade de Boa Vista, e com a colaboração de oito imigrantes surdos venezuelanos, bilíngues em LSV e Libras, envolveu o emprego do aparato teórico-metodológico da etnografia da comunicação de Hymes (1972; 1986). Os procedimentos de coleta envolveram a observação participante, com registro por meio de vídeo e apoio de anotações em diário de campo, além da aplicação um questionário respondido por escrito (em espanhol) pelos participantes, para uma análise qualitativa dos dados. Para os propósitos deste artigo, são analisados três eventos de fala com ocorrência de codeswitching como escolha marcada.

A organização do artigo contempla, na próxima seção, um meIhor delineamento da abordagem teórica adotada. Na seção seguinte, detalhamos os procedimentos metodológicos que orientaram a seleção dos sujeitos, assim como o processo de coleta e seleção dos dados. Em seguida, são apresentados os dados de CS e as análises em conformidade com os pilares teóricos da pesquisa, levando, na seção final, para algumas conclusões, limitações e contribuições do estudo.

\section{Referencial teórico}

\section{As premissas do Modelo de Escolha Racional (ER)}

A linguista estadunidense Carol Myers-Scotton elaborou, a partir de seus estudos na década de 1980 no Quênia e Zimbábue, no 
Codeswitching entre línguas de sinais e as escolhas linguísticas de surdos venezuelanos no Brasil Rodrigo Mesquita - Alessandra Cruz

continente africano, uma série de modelos teóricos para a análise de fenômenos de contato oriundos do bilinguismo, em especial, o codeswitching. Os modelos elaborados pela autora (individualmente ou em parcerias com outras linguistas) são complementares entre si e buscaram oferecer suporte para análise das restrições linguísticas em tipos específicos de CS e também para as motivações sociopragmáticas dos fenômenos, considerando a ampla tipologia através da qual o CS se apresenta ${ }^{4}$. Para os nossos propósitos, elegemos dois destes modelos: a teoria de Escolha Racional (ER) e o Modelo de Marcação (MM). O primeiro oferece o suporte teórico necessário para que o segundo se apresente como ferramenta eficiente para a análise das motivações sociopsicológicas do CS.

O pressuposto básico do modelo de Escolha Racional (MYERS-SCOTTON; BOLONIAY, 2001) é de que escolhas linguísticas subjetivas e racionais são orientadas por cálculos cognitivamente baseados, ou seja, por propósitos objetivos, levando em consideração o comportamento dos demais envolvidos na interação. Tal pressuposto abre caminho para que seja possível identificar escoIhas linguísticas orientadas por propósitos objetivos dos falantes. Isso requer que seja identificada a "recompensa" ou "reward" (MYERS-SCOTTON; BOLONYAI, 2001, p. 22) por trás da escolha linguística do falante.

A partir da correlação, no modelo da Escolha Racional, entre a escolha da língua e intenção dos indivíduos de agir racionalmente, busca-se, nas evidências disponíveis - no nosso caso, dados de codeswitching envolvendo o par linguístico LSV e Libras -, identificar cálculos cognitivamente baseados. Para isso, o Modelo de Marcação de Myers-Scotton (1993) apresenta-se como suporte teórico relevante por pressupor uma "métrica de marcação", ou seja, uma estrutura cognitiva universal que permite aos indivíduos bilíngues avaliarem as consequências da marcação (ou não) de escolhas de línguas. Conforme Myers-Scotton,

4 A tipologia de codeswitching, assim como os demais modelos teóricos de Carol Myers-Scotton para análise do fenômeno não são o foco deste artigo. Para uma discussão mais ampla a respeito desses assuntos, veja Mesquita (2015). 
Codeswitching entre línguas de sinais e as escolhas linguísticas de surdos venezuelanos no Brasil Rodrigo Mesquita - Alessandra Cruz

a teoria subjacente ao modelo de marcação propõe que os falantes possuem um senso de marcação que considera os códigos linguísticos disponíveis para qualquer evento, mas escoIhem seus códigos com base na pessoa e/ou na relação com outros que eles desejam estabelecer. Esta marcação tem uma base normativa dentro da comunidade e os falantes também sabem as consequências de escolhas marcadas ou não-marcadas. Sendo a escolha não marcada mais 'segura' (isto é, não gera surpresas porque indexa uma relação interpessoal esperada), os falantes geralmente fazem esta escolha. Mas nem sempre. Os falantes avaliam os custos e recompensas potenciais de todas as escolhas alternativas e fazem suas decisões. (MYERS-SCOTTON, 1993 apud MESQUITA, 2015, p. 109).

A competência comunicativa dos indivíduos, como se sabe desde os primeiros pressupostos chomskyanos, envolve estruturas inatas, mas também, como ressalta Myers-Scotton (2006, p. 159), "inclui o que é armazenado e agregado no curso do uso da linguagem". Isso implica dizer que o indivíduo, a partir de sua competência comunicativa e experiência social, desenvolve a percepção de que há uma espécie de continuum multidimensional de opções para tipos específicos de interação que vai de mais socialmente não marcado, em um dos polos, a mais marcado, em outro. Esta é, conforme Myers-Scotton e Boloniay (2001, p. 8), a mais importante habilidade que a capacidade de marcação, tal como um construto sociolinguístico, desenvolve nos indivíduos bilíngues. Outras duas habilidades são relativas (i) ao aprendizado da natureza dinâmica da ordem de marcação, que depende de tipos específicos de interação e do desenvolvimento das interações individuais e (ii) ao desenvolvimento da capacidade de fornecer interpretações relevantes para todas as opções, marcadas e não marcadas, de acordo com o tipo de interação. 
Codeswitching entre línguas de sinais e as escolhas linguísticas de surdos venezuelanos no Brasil Rodrigo Mesquita • Alessandra Cruz

\section{As premissas do Modelo de Marcação (MM)}

Myers-Scotton e Boloniay (2001, p. 8-10) apresentam um esboço com as principais premissas do modelo anteriormente postulado em Myers-Scotton (1993), o qual traduzimos livremente e com adaptações - inclusive de exemplos - na sequência.

O MM pressupõe que, como parte de sua estrutura cognitiva geral, todos os falantes possuem um avaliador de marcação, um componente abstrato subjacente à capacidade de conceituar a marcação. O desenvolvimento de tal capacidade requer a exposição dos falantes ao uso de escolhas marcadas e não marcadas no discurso real da comunidade na qual está inserido ou pela qual transita.

Isso implica que o avaliador de marcação é um dispositivo dedutivo, que faz previsões sobre a marcação relativa, o que faz do dispositivo um processo para avaliar escolhas possíveis e não um conjunto de regras predefinidas.

Quanto às interpretações que indivíduos atribuem às escolhas linguísticas, estão relacionadas à projeção do falante sobre sua própria persona e às relações com outros participantes da interação. Assim, as escolhas dos falantes são percebidas como indexadoras de um conjunto de Direitos e Obrigações (DO) estabelecido entre os participantes, de forma que os participantes interpretam uma escolha determinada no contexto das opções que indexam o conjunto de DO mais não marcado, definido para um tipo de interação específico, da mesma forma que reconhecem algumas escolhas como indexadoras de conjuntos de DO mais marcados. Dessa forma, cada língua ou forma de utilização dos códigos presente na realidade de uma dada comunidade tem indexado um conjunto de DO. Tais conjuntos de DO são, portanto, elementos diretamente derivados de quaisquer fatores sociais salientes na comunidade e no tipo de interação.

Em contextos de fronteira, por exemplo, imigrantes bilíngues buscam utilizar a língua falada por interlocutores nativos, ainda 
Codeswitching entre línguas de sinais e as escolhas linguísticas de surdos venezuelanos no Brasil Rodrigo Mesquita - Alessandra Cruz

que estes sejam igualmente bilíngues e com domínio das mesmas línguas dos imigrantes. As motivações podem ser diversas, incluindo a necessidade de assimilação de uma cultura dominante, seja em contextos mais gerais e/ou específicos. De qualquer forma, as necessidades de convívio social e as configurações das interações podem estabelecer conjuntos de DO em que a escolha da língua nativa indexa a opção mais não marcada.

A marcação de um conjunto de DO para uma interação específica está sujeita à mudança, a depender de alterações nos componentes situacionais ou da negociação dos participantes no desenrolar das interações, o que pode ocasionar uma consequente mudança na marcação da escolha linguística em curso para a interação. Por esta razão, não há escolhas universalmente não marcadas ou conjuntos de DO universalmente não marcados, ainda que em uma mesma comunidade. Considerando o mesmo exemplo anterior, uma família de imigrantes pode ter indexada a primeira língua (por exemplo, a LSV) como opção não marcada para um conjunto de DO quando há apenas membros da família e pode mudar para um conjunto de DO em que a língua do outro (por exemplo, a Libras) é a escolha não marcada a partir do momento em que recebe uma visita de um nativo (por exemplo, um/a brasileiro/a usuário da Libras).

Por uma variedade de razões, os indivíduos selecionam com mais frequência a escolha linguística que indexa o que eles consideram como o conjunto de DO mais não marcado, algo como "negociar como de costume", o que significa que os indivíduos aceitam as visões predominantes da comunidade para um conjunto apropriado de DO, considerando quem são os participantes, bem como outros fatores situacionais.

No entanto, os falantes podem fazer escolhas marcadas e, quando o fazem, sabem que tal escolha será vista como a negociação de algum conjunto de DO outro, diferente do conjunto de DO não marcado. Quando isso ocorre, os indivíduos negociam a alteração do conjunto de DO corrente (não marcado) para um novo conjunto de DO marcado, que, por sua vez, pode passar a ser o 
Codeswitching entre línguas de sinais e as escolhas linguísticas de surdos venezuelanos no Brasil Rodrigo Mesquita • Alessandra Cruz

índice não marcado da interação, e assim por diante. Análises de exemplos de CS como escolhas marcadas, a propósito, são o foco deste artigo.

\section{Aplicação do MM aos dados de codeswitching}

O modelos elaborados por Myers-Scotton e suas colaboradoras foram aperfeiçoados para lidar com fenômenos de contato de uma forma geral, seja envolvendo pares linguísticos ou mesmo variedades de uma mesma língua, em situações de acomodação linguística, em que operam motivações socioculturais. No entanto, é na análise de dados de codeswitching (CS) que os modelos teóricos encontraram maior aplicação na literatura da área, mesmo na formulação teórica de Myers-Scotton (1993), que analisou dados de CS coletados em Nairóbi, no Quênia.

Para a autora, o CS "pode ocorrer entre falantes, ou entre sentenças no turno de um mesmo falante, ou dentro de uma mesma sentença" (MYERS-SCOTTON, 2006, p. 161). Em suma, Myers-Scotton (1993), a partir das premissas do MM, enumera quatro tipos de CS:

a) CS como uma sequência de escolhas não marcadas, em que cada língua utilizada é a escolha não marcada em decorrência de mudanças devidas aos requisitos do contexto social ou outras instâncias do contexto interacional como, por exemplo, quando há bilíngues e monolíngues envolvidos na interação e o falante bilíngue precisa acomodar suas escolhas à língua dominada pelos interlocutores.

No exemplo (1), Olívia e Myha são surdas venezuelanas bilíngues, têm a LSV como primeira língua (L1) e são proficientes na Libras. A pesquisadora, que é brasileira, domina a Libras e tem domínio limitado da LSV. O evento - uma festa de aniversário - se dá no Brasil, na casa das primeiras, com a presença da pesquisadora. A interação vem acontecendo em Libras, que indexa o conjunto de Direitos e Obrigações (DO) não marcado na interação. Quando Olí- 
Codeswitching entre línguas de sinais e as escolhas linguísticas de surdos venezuelanos no Brasil Rodrigo Mesquita • Alessandra Cruz

via pede a Myha que chame a filha para cantar parabéns (linha 1), o uso de CS passa a ser a nova escolha não marcada para o novo conjunto de DO. Isso porque Olívia e Myha sabem que a criança de cinco anos ainda tem domínio muito limitado da Libras e Olívia faz questão de usar a expressão "ANIVERSÁRIO AGORA" ("[vamos] cantar parabéns agora') em LSV, indicando a forma como a mensagem deve ser repassada à criança. Em seguida (linhas 5 e 6), Myha volta a utilizar a Libras quando se dirige à pesquisadora, alterando novamente para o conjunto de DO em que a Libras é a escolha não marcada.

(1) Hora de cantar parabéns (CRUZ, 2019, p. 99)

1 Olívia: FALAR L-Y-S VIR ANIVERSÁRIO AGORA!

'Fale para Lys vir cantar parabéns agora.'

2 Myha: ONDE ESTÁ L-Y-S?

'Onde está a Lys?'

3 Olívia: BRINCAR QUARTO.

'Está brincando no quarto.'

4 Myha [para a criança]: AGORA COMER BOLO? MAMÃE FALAR "ANIVERSÁRIO AGORA".

'Vamos comer bolo agora? Mamãe falou para ir cantar parabéns.'

5 Myha [para a pesquisadora]: ELA CINCO IDADE. 3sNÃO-SABER LIBRAS BEM. LSV SIM 3sSABER

6 BEM 3SCONHECER SEMPRE

'Ela tem cinco anos de idade. Não sabe bem a Libras. A LSV ela conhece bem.' 5 Neste e nos demais exemplos neste artigo, nas glosas que representam a transcrição dos sinais utilizados - sempre em CAIXA
ALTA -, a marcação em itálico sublinhado representa o uso da LSV e onde não há marcaçãa, a Libras. Todos os nomes são fictícios e seguem os mesmos nomes utilizados em Cruz (2019). As glosas representadas com a utilização de traços (como em L-Y-S, por exemplo) foram utilizadas com o recurso da datilologia. 
Codeswitching entre línguas de sinais e as escolhas linguísticas de surdos venezuelanos no Brasil Rodrigo Mesquita • Alessandra Cruz

b) o próprio CS como a escolha não marcada, situação em que os falantes procuram utilizar o CS para indexar o conjunto não marcado de DO em que, por exemplo, estão envolvidos interlocutores bilíngues que são pares.

No exemplo (2), Maryha e Levi são um casal de surdos bilíngues venezuelanos que dominam com fluência a LSV (primeira língua - L1 - de ambos) e Libras e foram levar o filho recém-nascido ao hospital. O bebê está no colo de Maryha. A interação se dá em Libras até que o sinal para 'MÊS' precisa ser usado, o que exigiria que Maryha utilizasse as duas mãos. Ela então alterna para a LSV (linha 3), língua em que o sinal pode ser realizado com apenas uma das mãos, complementando a sentença na mesma língua. O marido, que também é bilíngue, já espera que o CS possa ser usado entre os dois naturalmente, o que faz com o conjunto de DO estabelecido entre o casal indexe o próprio CS como uma escolha não marcada.

(1) Preocupação com saúde do filho no hospital público (CRUZ, 2019, p. 103)

1 Maryha: 3sCHORAR 3SNÃO-DORMIR, 3STOSSIR, 3STOSSIR.

'Ele não dormiu, chorou, tem muita tosse.'

2 Levi: NÃO 3sTER FEBRE, SÓ ANTES ONTEM 3sTER.

'Ele não tem febre, só antes de ontem.'

3 Maryha: 1SPREOCUPAR AMIGA 3SFALAR “BEBÊ QUATRO MESES, PERIGOSO".

'Eu fico preocupada, minha amiga falou: "bebê só tem quatro meses", é perigoso.'

c) CS como uma escolha exploratória, em que o CS é utilizado para explorar ou negociar a escolha não marcada quando esta não está devidamente clara, em decorrência de situações específicas, 
Codeswitching entre línguas de sinais e as escolhas linguísticas de surdos venezuelanos no Brasil Rodrigo Mesquita • Alessandra Cruz

por exemplo, que sejam pouco experienciadas ou novas para os falantes.

Myha, neste exemplo (3), pede ajuda a uma interlocutora até então desconhecida (uma profissional de saúde indicada por outra pessoa) para tentar ajudar a amiga (Maryha) que está com o filho doente. Myha está bastante angustiada com a situação e, como é comum nesse tipo de situação (GROSJEAN, 1982), a L1 (no caso de Myha, a LSV) é escolhida. Sem saber (ou sequer perguntar) qual(is) língua(s) a interlocutora compreendia, Myha utiliza a Libras ("2sENTENDER?") para conferir se o conteúdo da sentença foi compreendido e segue novamente explicando a situação em LSV, enfatizando sua preocupação em Libras (linha 2) ao final do ato de fala. O CS Libras-LSV é utilizado por Myha para negociar um conjunto de DO não marcado em que possa ser melhor compreendida (e então, auxiliada) por sua interlocutora.

(1) Preocupação com criança doente em vídeo chamada com interlocutor desconhecido (CRUZ, 2019, p. 106 - 107)

1 Myha: M-A-R-Y-H-A 3SPRECISAR MÉDICO, 2sENTENDER? BEBÊ PERNILONGO, VERMELHO, 2 VERDADE, PREOCUPAD@!

'Maryha precisa ir ao médico, entendeu? Bebê está muito vermelho. Verdade. Estou preocupada, muito pernilongo!'

3 Interlocutor: O-K, 1sENTENDER!

'O-K, eu entendi.'

d) CS como uma escolha marcada, tipo no qual o CS é usado para estabelecer um outro conjunto de DO diferente do conjunto não marcado usual na comunidade, isto é, o falante utiliza o CS para não atender à expectativa da escolha esperada ou não cumprir uma norma social ou situacional esperada. Como já afirmado, esse é o tipo de CS que interessa aos propósitos deste artigo, em que buscamos analisar as negociações empreendidas pelos sujeitos bilíngues para alterarem conjuntos de DO suportados por 
Codeswitching entre línguas de sinais e as escolhas linguísticas de surdos venezuelanos no Brasil Rodrigo Mesquita - Alessandra Cruz

cálculos cognitivamente baseados. Três exemplos de CS como escolha marcada serão analisados. Antes, portanto, detalhamos os procedimentos metodológicos da pesquisa.

\section{Metodologia}

Neste artigo, revisitamos o banco de dados coletados para o trabalho de Cruz (2019), que realizou previamente um estudo descritivo tipológico e das funções sociais do CS envolvendo a Libras e a LSV. Embora os propósitos aqui sejam diferentes, o mesmo banco de dados foi utilizado.

O procedimento para a coleta de dados apoiou-se nos pressupostos teórico-metodológicos da Etnografia da Fala (HYMES, 1972; 1986), o que permitiu definir contornos mais precisos para a comunidade de fala e para os eventos de fala recorrentes entre os colaboradores. A comunidade de fala ${ }^{6}$, ou seja, o grupo de pessoas que compartilha regras de conduta e interpretação de fala (HYMES, 1972), foi definida para o presente estudo - seguindo Cruz (2019) como o grupo de imigrantes venezuelanos surdos que viviam em Boa Vista, Roraima.

Hymes (1972) esclarece que a comunidade de fala é fluida, o que significa que uma determinada comunidade pode conter outras e que um mesmo indivíduo pode transitar em diferentes comunidades, o que não restringe os participantes da pesquisa à comunidade de fala delimitada.

Da comunidade de fala de surdos venezuelanos em Boa Vista, participaram da pesquisa oito indivíduos bilíngues ${ }^{7}$, que possuem a LSV ou o espanhol (na modalidade escrita) como primeira língua (L1) e adquiriram a Libras (L2) em contato com surdos brasileiros.

\footnotetext{
6 Apesar de analisarmos aqui o contato entre línguas de sinais, portanto de sentenças sinalizadas e não faladas, no sentido literal da palavra "falar" (que pressupõe a oralização), optamos por manter a terminologia já largamente difundida da Etnografia da Comunicação, que não faz distinção entre línguas veiculadas por modalidade diferentes.

7 Todos os/as participantes assinaram os termos de concordância e participação na pesquisa, além de colaborarem ativamente em todas as suas etapas. Somos gratos a cada um/a deles/as.
} 
Codeswitching entre línguas de sinais e as escolhas linguísticas de surdos venezuelanos no Brasil Rodrigo Mesquita • Alessandra Cruz

Todos são, portanto, fluentes na LSV e também escrevem em espanhol.

A depender do tempo em que estão no Brasil, possuem domínio mais ou menos limitado da Libras. Todos são jovens adultos, vivem na mesma casa e têm idade entre 20 e 36 anos, sendo 4 pessoas do sexo masculino e 4 do sexo feminino. Neste artigo, nem todas elas participam dos exemplos analisados. Os exemplos foram selecionados não pelos sujeitos, mas sim, pelo tipo de CS aquele que representa escolhas marcadas nos eventos de fala.

Conforme explica Hymes (1972), o conceito de eventos de fala foi cunhado para que a consideração do contexto das interações pudesse abarcar as ocasiões ou aspectos das atividades sociais sempre governadas por normas socioculturalmente definidas - da comunidade de fala.

Os eventos de fala, observados entre 2017 e 2019, incluem: i) as interações cotidianas em contexto familiar; ii) eventos +- públicos, ocorridos em ambiente familiar, mas com presença de outras pessoas como, por exemplo, festas de aniversário ou outras comemorações; e iii) eventos em locais públicos, tais como bancos, hospitais ou demais agências de atendimento público. Os registros foram feitos com recurso audiovisual. Além dos vídeos registrados com a técnica de observação participante, própria da perspectiva etnográfica, os participantes da pesquisa responderam a um questionário semiestruturado. O espanhol - na modalidade escrita - foi a língua utilizada por todos eles para as respostas. Tais respostas foram complementares para a análise qualitativa dos dados, assim como as observações de diário de campo que se seguiram aos registros.

Em cada um dos eventos de fala, além dos sujeitos da pesquisa, estavam envolvidos interlocutores com diferente domínio das línguas de sinais ou mesmo sem domínio das línguas ou de uma delas. Além disso, em cada evento, há diferentes relações hierárquicas entre os envolvidos e propósitos igualmente distintos por parte dos colaboradores da pesquisa. A observação de cada um 
Codeswitching entre línguas de sinais e as escolhas linguísticas de surdos venezuelanos no Brasil Rodrigo Mesquita - Alessandra Cruz

desses fatores - e de outras evidências disponíveis do macrocontexto social - foi importante para interpretar a marcação ou não das escolhas linguísticas dos indivíduos, no uso do CS, em conformidade com o Modelo de Marcação de Myers-Scotton (1993) e os pressupostos da teoria de Escolha Racional (MYER-SCOTTON; BOLONYAI, 2001). Como afirmamos na seção anterior, serão analisados três exemplos de CS como escolha marcada, ou seja, como estratégias cognitivamente baseadas para alterar conjuntos de direitos e obrigações estabelecidos pela comunidade de fala.

Para a transcrição dos dados, utilizamos o sistema de glosas para representação dos sinais em ambas as línguas, como já explicitado nos exemplos da seção anterior. As glosas com marcação em itálico sublinhado representam os sinais em LSV e as glosas sem marcação representam os sinais em Libras, como também já foi esclarecido. Especificamente para alguns sinais utilizados na LSV, por serem menos conhecidos na comunidade brasileira e para melhor visualização nas análises, foram utilizadas imagens fotográficas com a técnica da ilusão de movimento. Os nomes são fictícios para preservação da identidade dos/as participantes.

\section{Análise de dados}

No primeiro exemplo analisado nesta seção (exemplo 4), o evento ocorre em ambiente familiar, com a participação de Myha e da pesquisadora (P). Myha é fluente na LSV (sua L1) e tem boa proficiência em Libras, proporcionada pela sua permanência no Brasil há mais de dois anos. A pesquisadora é fluente em Libras e tem proficiência limitada em LSV, o que é de conhecimento de Myha.

(1) Saudades da família que está na Venezuela (CRUZ, 2019, p. 101)

1 Myha: 1sTER SAUDADEmuito MINHA FAMÍLIA, MEUS FILHOS DOIS.1SPREOCUPAD@. MÃE 2 MINHA 3SCUIDAR. 
Codeswitching entre línguas de sinais e as escolhas linguísticas de surdos venezuelanos no Brasil Rodrigo Mesquita • Alessandra Cruz

'Eu tenho muita saudade da minha família, dos meus dois fiIhos. Eu fico preocupada. Minha mãe cuida deles.'

3 P: VOCÊ FALAR SEMPRE FILHOS? SABER 3PESTAR BEM?

'Você fala sempre com seus filhos? Sabe se eles estão bem?'

4 Myha: SIM, MÃE 2sENVIAR VÍDEO WHATSAPP, 2sFALAR: “ELES SAUDADESmuito, ESTAR 5 MAGROSmuito"

‘Sim, minha mãe envia vídeos pelo WhatsApp. Ela falou "eles têm saudades e estão magrinhos"'.

Como estratégia deliberada de Myha, a Libras é a escolha natural dela (e dos demais membros da comunidade de fala) no Brasil, especialmente quando há interlocutores brasileiros (ainda que com alguma proficiência na LSV) envolvidos na interação e, portanto, a escolha da Libras indexa o conjunto de direitos e obrigações (DO) não marcado para tais circunstâncias. Myha afirma que geralmente usa a Libras

(1) porque el lenguage de señas brasilero es lo que se utiliza aqui en Brasil y es la manera en como quedo hablar con sordos brasileros.

'porque a língua de sinais brasileira é o que se utiliza aqui no Brasil e é a maneira como quero falar com os surdos brasileiros'.

Dessa forma, a escolha do sinal 'SAUDADE' (Figura 1) em LSV na linha 1 representa uma escolha marcada, considerando que Myha conhece o sinal em Libras e esta seria a escolha que indexa o conjunto de DO não marcado para a interação. Há, pelo menos, duas evidências para indicar a motivação de Myha: uma relacionada ao conteúdo e outra ao sequenciamento da interação. 


\section{Figura 1 - Sinal 'SAUDADE' em LSV}

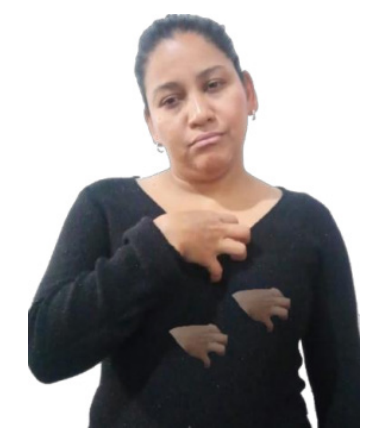

Fonte: Cruz (2019, p. 101)

A marcação, como mostraram Myers-Scotton e Bolonyai (2011), pode ser um recurso utilizado para atenuar ou enfatizar o conteúdo de uma sentença ou parte dela. Em relação ao conteúdo, Myha, movida pelo intuito de colocar ênfase na saudade que sentia dos filhos, escolhe a forma em LSV para acentuar seu sentimento e permitir que o interlocutor o perceba melhor. Agrega-se a isso o fato de que Myha utiliza o sinal com intensificadores não manuais, como a expressão facial marcada e o vigor nos movimentos que compõem o sinal.

Além disso, na sequência da interação (linha 4) Myha fala sobre um vídeo que recebeu da mãe (que está na Venezuela) e cita uma fala dela em que o sinal 'SAUDADE' - no caso, a sentença completa - também é utilizado em LSV. Como mostrou Cruz (2019), a função de citação descrita por Gumperz (1988) ajuda a entender o uso do CS e, neste caso, configura-se como uma sequência de CS não marcado, pois está clara a intenção de reproduzir a fala da mãe. No entanto, tal citação também evidencia a estratégia sociopsicológica que motivou a escolha marcada com o sinal em LSV na linha 1. Na sequência da passagem (linhas 1 e 2), Myha fala da mãe e, possivelmente, já recuperava a imagem dela no vídeo explicitado na linha 4 e, juntamente à imagem da mãe, a imagem do sinal utilizado por ela.

No exemplo (6), Alejandro participa de uma palestra na Universidade Federal de Roraima, em Boa Vista. Ele é venezuelano e 
Codeswitching entre línguas de sinais e as escolhas linguísticas de surdos venezuelanos no Brasil Rodrigo Mesquita - Alessandra Cruz

tem LSV como L1, espanhol como L2 (na modalidade escrita), tem domínio da Libras e está adquirindo também o português na modalidade escrita. Também participam do evento outros surdos venezuelanos e brasileiros, além de ouvintes que dominam a Libras. A palestrante ministra a conferência em Libras e as interações ocorrem nesta língua. Está estabelecido, portanto, o conjunto de DO em que a Libras é escolha não marcada. Após uma explicação da palestrante a respeito de empréstimos do português para Libras (recurso da datilologia) e da abertura para o público presente se manifestar, Alejandro comenta (linhas 3 e 4) sobre a sua dificuldade para aprender português e alterna entre as duas línguas de sinais.

(1) Participação em palestra sobre usos da Libras e do português (CRUZ, 2019, p. 108 - 109)

1 Palestrante: VOCÊS 3pVER DATILOLOGIA? NÃO, SINAIS SÓ SINAIS. DATILOLOGIA PORTUGUÊS, 2 EMPRÉSTIMO LÍNGUISTICO, NÃO LIBRAS. ALGUÉM QUER PERGUNTAR?

'Vocês viram datilologia? Não, são apenas sinais. Datilologia é português,

é empréstimo linguístico, não é Libras. Alguém tem alguma pergunta?'

3 Alejandro: O-K, PORTUGUÊS DIFÍCIL. NÓS VENEZUELA ESPANHOL LSV,

4 3SENTENDER? 2SPRECISAR LIBRAS E PORTUGUÊS, ENTENDER?

‘Ok, português é difícil. Nós somos da Venezuela, lá temos espanhol e LSV,

entendeu? Precisamos de Libras e português, entendeu?'

5 Palestrante: SIM 1sENTENDER, VOCÊS AGORA AQUISIÇÃO DUAS LÍNGUAS NOVAS. 
Codeswitching entre línguas de sinais e as escolhas linguísticas de surdos venezuelanos no Brasil Rodrigo Mesquita • Alessandra Cruz

'Sim, entendi, vocês agora estão adquirindo duas línguas novas.'

6 Alejandro: VERDADE, 3sNÃO-PRECISAR. 1sENTENDER.

'Verdade, não precisa. Entendi.'

No exemplo (6) há alta incidência de CS, de forma que é difícil afirmar qual língua fornece o quadro morfossintático no qual a outra encaixa. Em todas as sentenças, há CS intrassentencial (ou seja, dentro de uma mesma sentença) e a LSV é a escolha para os nomes 'DIFÍCIL', 'ESPANHOL' e 'LSV', o pronome pessoal 'NÓS' e o verbo 'PRECISAR'.

Figura 2 - Sinais utilizados por Alejandro em LSV

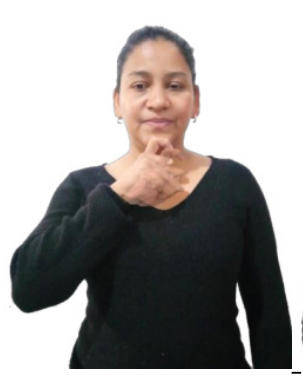

DIFÍCIL

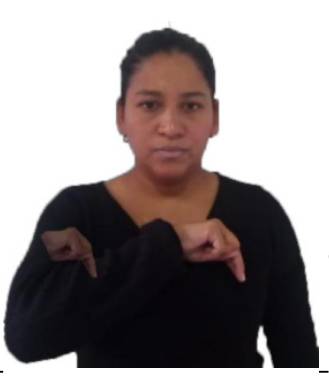

NÓs

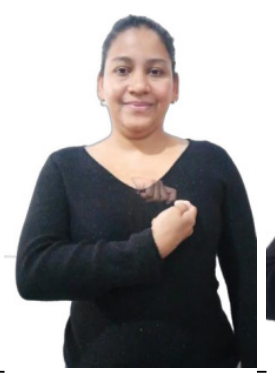

ESPANHOL

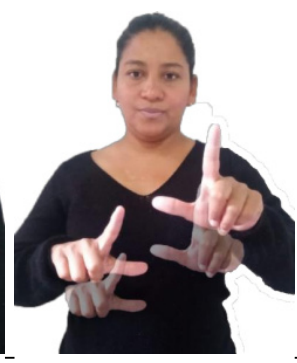

LSV

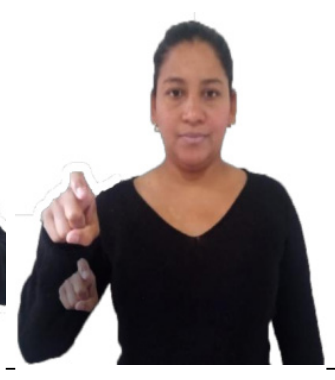

PRECISAR

Fonte: Cruz (2019, p. 108)

Em Libras, foram utilizados os nomes 'PORTUGUÊS', 'LIBRAS', 'VENEZUELA' e a forma verbal 'ENTENDER' que, utilizada de forma interrogativa, também pode funcionar como um marcador discursivo que fecha sentenças. Aparentemente, não há motivo para justificar o uso da LSV no contexto situacional em que a escolha da Libras indexa o código não marcado no conjunto de DO estabelecido pelas circunstâncias da interação, mas isso exige ainda mais atenção. Além disso, a possibilidade de uso do CS para preenchimento de lacunas lexicais é possível, dado a proficiência limitada de Alexandro na Libras, mas não justifica o uso de todos os sinais 
Codeswitching entre línguas de sinais e as escolhas linguísticas de surdos venezuelanos no Brasil Rodrigo Mesquita - Alessandra Cruz

empregados na LSV, que são amplamente conhecidos e foram, inclusive, compartilhados em outros momentos da palestra. O sinal para o verbo 'PRECISAR', por exemplo, é posteriormente utilizado em Libras na linha 6, o que demonstra que era conhecido por Alejandro também nesta língua. Ainda sobre o conteúdo dos itens lexicais utilizados, é relevante observar que os sinais utilizados para as línguas brasileiras (português e Libras) foram realizados em Libras, da mesma forma como os sinais utilizados para as línguas venezuelanas (espanhol e LSV) foram utilizados em LSV. O fato do sinal 'VENEZUELA' ter sido utilizado em Libras é curioso por contrariar o que parece ser, a princípio, uma estratégia de escolha das línguas baseada no conteúdo.

Na perspectiva do modelo de ER, como já ressaltamos, é necessário identificar a "recompensa" ou "reward" (MYERS-SCOTTON; BOLONYAI, 2001, p. 22) por trás da escolha linguística do falante. Para isso, é preciso considerar que i) Alejandro está entre os mais participativos durante a palestra; ii) a palestra trata sobre relações entre línguas e a Libras é apontada em alguns momentos como língua minorizada em relação ao português, o que explica a adoção de empréstimos da língua majoritária (português) para a Libras e não o contrário; e iii) a palestra é ministrada por uma professora surda brasileira, que demonstra em vários momentos solidariedade em relação à comunidade de imigrantes surdos venezuelanos e valoriza a diversidade linguística.

Ao considerar tais fatores, pode-se creditar a "recompensa" de Alejandro à afirmação de sua identidade linguística e cultural, além de valores relacionados. Ao optar pela escolha marcada, ou seja, o uso do CS como uma escolha marcada, Alejandro negocia com a palestrante - considerando a oportunidade dada por ela, hierarquicamente superior na interação - a alteração do conjunto de DO atual (Libras como escolha não marcada) para um novo conjunto de DO, no qual o próprio CS Libras-LSV indexa a nova escolha não marcada. Ao negociar o novo conjunto de DO, Alejandro busca legitimar a LSV, ao lado da Libras, como mais uma língua pertencente à comunidade surda local, ao mesmo tempo 
Codeswitching entre línguas de sinais e as escolhas linguísticas de surdos venezuelanos no Brasil Rodrigo Mesquita • Alessandra Cruz

em que reafirma "precisar" da Libras e do português, línguas majoritárias no contexto brasileiro (o português em relação à Libras e as duas línguas em relação à LSV). No questionário aplicado junto aos colaboradores da pesquisa, a intenção de Alejandro de cultivar valores interculturais também ajuda a entender suas escolhas racionalmente guiadas. Quando perguntado por que utiliza a Libras, ele responde:

(1) "Porque lengua de seña Brasil diferente, como aprendo me gusta, y asi cultura Boa Vista y yo costumbre Venezuela."

Além disso, Alejandro afirma ter facilidade para aprender Libras (ao contrário do que afirmou para a palestrante, no exemplo (6), em relação ao português):

(1) "Aqui hay persona sordo, mucho señas y solo ver que aprendo."

'Aqui têm pessoas surdas, muitos sinais e é só ver que eu aprendo.'

No próximo exemplo (9), três colaboradores bilíngues (com diferente níveis de proficiência em Libras) e a pesquisadora estão fazendo um lanche e, como é de costume durante as refeições, fazem comentários sobre a comida. O evento, ainda que em ambiente familiar e com presença majoritária de indivíduos que possuem a LSV como L1, se dá em Libras, possivelmente por deferência à dona da casa (a pesquisadora) e à sua limitação na LSV.

O conjunto de DO não marcado, neste exemplo, indexa a Libras como escolha não marcada. Ao experimentar um doce preparado pela anfitriã, Maryha realiza um sinal híbrido para o item lexical 'DELÍCIA' de forma muito marcada, por ser composta por morfemas das duas línguas. Ela o faz de forma sorridente e com 
Codeswitching entre línguas de sinais e as escolhas linguísticas de surdos venezuelanos no Brasil Rodrigo Mesquita - Alessandra Cruz

o olhar voltado para Jorman, que ainda possui domínio limitado da Libras por ter chegado mais recentemente ao Brasil. O sinal é repetido três vezes, num gesto de divertimento com o amigo e os demais presentes.

(1) Comentários sobre o lanche (CRUZ, 2019, p. 131)

Jorman: BOM [faz sinal positivo enquanto come]

'Que bom!'

Maryha: DELÍCIA DELÍCIA DELÍCIA.

'Uma delícia, delícia mesmo, uma delícia!'

P: 2sGOSTAR?

'Gostou?'

O clima é de descontração e cumplicidade entre os participantes do evento. Há uma atitude comum entre a comunidade de surdos imigrantes, que é ensinar a Libras uns aos outros, da mesma forma que procuram aprender quando há usuários da Libras presentes nas interações. Cruz (2019, p. 124 - 125) afirma que observou "em outros eventos de fala, que os participantes de pesquisa também perguntavam como realizar determinados sinais em Libras, demonstrando o interesse em aprender e usar a língua de sinais brasileira." O grupo chegou gradativamente e os que estão há mais tempo no Brasil, como é o caso de Maryha, costumam ensinar sinais aos que chegaram mais recentemente - como é o caso de Jorman.

O evento durou toda uma tarde e, ainda que tenha ocorrido CS Libras-LSV em outros instantes, no momento que o exemplo (9) ocorreu, o conjunto de DO não marcado tinha indexado o uso da Libras como escolha não marcada. O switch envolvendo o uso do sinal com elementos das duas línguas é bastante marcado e demonstra alta proficiência bilíngue de Maryha. Os respectivos sinais para 'DELíCIA' em LSV e Libras possuem, em comum, o mesmo 
Codeswitching entre línguas de sinais e as escolhas linguísticas de surdos venezuelanos no Brasil Rodrigo Mesquita • Alessandra Cruz

ponto de articulação. Se diferenciam, de forma mais evidente, pela configuração de mão e o pelo movimento que, na Libras, é retilíneo da direita para a esquerda e, na LSV, há além do movimento idêntico ao da Libras, um movimento da esquerda para a direita. Maryha inicia o sinal em Libras (com movimento da esquerda para a direita) e termina em LSV, com movimento em sentido contrário e com uma mudança na configuração de mão, como na Figura 3.

\section{Figura 3 - Sinal híbrido (LSV e Libras) para a palavra DELíCIA}

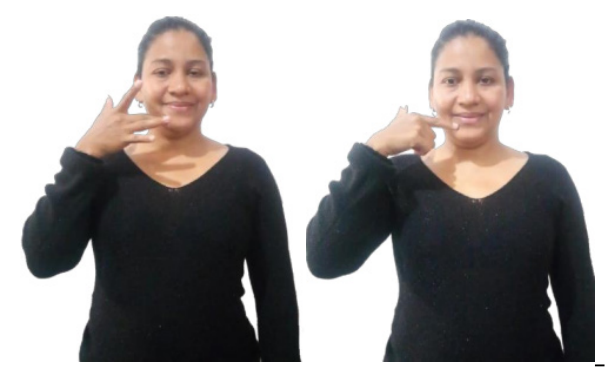

Fonte: Cruz (2019, p. 131)

A marcação da escolha de Maryha, como postula o modelo de ER, também aponta para recompensas recuperáveis através das evidências do contexto. O clima descontraído do ambiente familiar e a ausência de uma hierarquia marcada em uma relação entre amigos são fatores que contornam o tipo de interação. Soma-se a isso a solidariedade entre os membros da comunidade de imigrantes como um fator recorrente e, ainda, pensando-se no conteúdo do sinal utilizado, o enfático elogio ao alimento saboreado. Myers-Scotton e Bolonyai (2011) explicam que as interpretações que os falantes atribuem às escolhas linguísticas estão relacionadas tanto à sua própria projeção de personalidade quanto às relações com os outros, o que, no caso do exemplo, projeta (e recompensa) Maryha como um membro solidário do grupo.

Dito de uma outra forma, a marcação do código, no exemplo (9), e a negociação para a indexação de um novo conjunto de DO não marcado apontam para as recompensas que Maryha pode lograr, tal como o reconhecimento como um membro solidário da 
Codeswitching entre línguas de sinais e as escolhas linguísticas de surdos venezuelanos no Brasil Rodrigo Mesquita - Alessandra Cruz

comunidade e que nela deseja assim permanecer. Isso foi possível recuperar ao considerar que as duas línguas de sinais são utilizadas (e alternadas) com propósito de: i) ensinar um novo sinal para um dos participantes; ii) brincar com a situação e contribuir para (a manutenção de) uma interação amigável; e iii) elogiar enfaticamente o sabor do alimento oferecido por outro participante.

\section{Considerações finais}

O alcance das análises, como em qualquer teoria, é limitado. Não se esperou neste artigo explicar o caráter ou caracterização dos grupos sociais envolvidos. No entanto, foi possível entender melhor o que as pessoas fazem diante de determinadas situações, oferecendo melhores explicações a respeito "do tecido da sociedade e a interação social" (MYERS-SCOTTON; BOLONYAI, 2001, p. 6)

Em suma, conforme o Modelo de Marcação (MM), cada código (ou língua) presente na realidade de uma comunidade tem indexado um conjunto do DO, que pode mudar conforme as circunstâncias sociais e/ou situacionais de cada interação. As escoIhas linguísticas refletem, portanto, as negociações que os falantes empreendem para alcançar seus objetivos, levando em consideração as possíveis consequências de cada escolha. Nos dados de CS envolvendo as línguas LSV e Libras, buscamos identificar como as escolhas marcadas indexam negociações dos indivíduos para estabelecer novos conjuntos de DO em que coexistem suas identidades linguísticas e culturais e as novas necessidades comunicativas, que envolvem o uso da Libras e também da língua portuguesa.

Sob os pressupostos do modelo de Escolha Racional, nos exemplos de CS selecionados para análise neste artigo, procuramos ver como surdos bilíngues venezuelanos empregam o CS, como uma escolha racionalmente marcada, e como isso está relacionado com estratégias cognitivas para a otimização das recompensas, sejam elas comunicativas - para se fazer compreender melhor -, sejam 
Codeswitching entre línguas de sinais e as escolhas linguísticas de surdos venezuelanos no Brasil Rodrigo Mesquita - Alessandra Cruz

para reafirmar suas identidades nacionais, socioculturais e linguísticas ou de pertença a grupos identificados por uma solidariedade mútua entre os indivíduos, em um contexto muitas vezes hostil e segregado linguística e socialmente. A busca por melhor adaptação ao novo contexto e por melhores condições de vida, portanto, é uma recompensa subjacente em todos os exemplos.

Nesta busca, a comunidade surda boa-vistense e a Libras, língua natural dessa comunidade e minorizada em relação ao português, desponta como o principal meio para a inclusão dos imigrantes venezuelanos no Brasil, ainda que a LSV seja minoritária em relação à Libras. A solidariedade entre a comunidade surda de Boa Vista e a de imigrantes venezuelanos apresenta-se, num contexto de diversidade de grupos populacionais, muitas vezes conflitantes, como uma estratégia possível de (r)existência para os grupos minoritários.

Espera-se, com este estudo, além da contribuição para as teorias do contato linguístico, especialmente para os modelos de análise do bilinguismo individual elaborados por Myers-Scotton e colaboradoras, contribuir para as ações de acolhimento aos imigrantes no Brasil através do melhor entendimento dos diálogos interculturais. Ainda que indiretamente, espera-se também contribuir para que os colaboradores desta pesquisa alcancem seus objetivos, especialmente no que diz respeito às melhores condições de vida almejadas, como ilustra o desejo de Alejandro no exemplo que fecha este texto:

(1) "Que este pais me ayuda en calidad vida, un que en mi pais no la hay."

'Que este país possa me ajudar a obter mais qualidade de vida, o que em meu país já não há'. 
Codeswitching entre línguas de sinais e as escolhas linguísticas de surdos venezuelanos no Brasil Rodrigo Mesquita - Alessandra Cruz

\section{Referências}

CRUZ, A. P. da. Contato entre línguas de sinais: um estudo sociolinguístico sobre o code-switching no contexto fronteiriço Brasil e Venezuela. Dissertação (Mestrado em Letras). Universidade Federal de Roraima, Boa Vista - RR, 2019.

GÓES, M. C. R.; LACERDA, C. B. F. Surdez: processos educativos e subjetividade. São Paulo: Lovise, 2000.

GROSJEAN, F. Life with two languages: an introduction to bilingualism. Cambridge: Harvard University Press, 1982.

GUMPERZ, J. Discourse strategies. Cambridge: Cambridge University Press, 1988.

HYMES, D. Toward ethnographies of communication: the analysis of communicative events. In: GIGLIOLI, P. P. (Ed.). Language and social context. Harmonds worth: Penguin Books, 1972 [1964]. p. 21-43. HYMES, D. Models of the interaction of language and social life. In.: GUMPERZ, J. J.; HYMES, D. (Ed.). Directions in Sociolinguistics: The Ethnography of Communication. New York: Holt, Rinehart, Winston, 1986. p. 35-71.

MESQUITA, R. Code-switching em Akwẽ-Xerente/Português. Tese (Doutorado em Letras e Linguística) - Faculdade de Letras, Universidade Federal de Goiás, Goiânia, 2015.

MESQUITA, R. "Diaria o fixo": fotografias sociolinguísticas de Boa Vista Roraima e as novas perspectivas para as pesquisas do contato linguístico na fronteira. In.: CRUZ, A.; ALEIXO, F. (Orgs.). Roraima entre línguas: contatos linguísticos no universo da tríplice fronteira do extremo-norte brasileiro. Boa Vista: Editora da UFRR, 2020. p. 48-78.

MORALES, A. M. Algunas consideraciones para la implementación de políticas educativas para personas sordas en Venezuela. Laurus, Caracas, v. 13, n. 1, p 25-38, 2006.

MYERS-SCOTTON, C. Social Motivations for Codeswitching: evidence from Africa. New York: Oxford University Press, 1993. 
Codeswitching entre línguas de sinais e as escolhas linguísticas de surdos venezuelanos no Brasil Rodrigo Mesquita - Alessandra Cruz

MYERS-SCOTTON, C. Multiple voices: an introduction to bilingualism. Malden: Blackwell Publishing, 2006.

MYERS-SCOTTON, C.; BOLONYAI, A. Calculating Speakers: Codeswitching in a Rational Choice Model. Language in Society, Cambridge, v. 30, n. 1, p. 1-28, 2001. 